\title{
Bilateral Uterine Artery Ligation and Square Sutures versus a Novel Combined Suture for Controlling Bleeding from the Placental Bed in Placenta Previa Centralis at Cesarean Section: A Randomized Clinical Trial
}

\author{
Mohamed Rezk*, Ibrahim Saif El-Nasr \\ Department of Obstetrics and Gynecology, Faculty of Medicine, Menoufia University, Shibin El-Kom City, \\ Menoufia governorate, Egypt
}

*Corresponding Author: Mohamed Rezk, Department of Obstetrics and Gynecology, Faculty of Medicine, Menoufia University, Shibin El-Kom City, Menoufia governorate, Egypt,Email: m_rezk9207@yahoo.com

\begin{abstract}
Objective: To assess the efficacy and safety of bilateral uterine artery ligation and square sutures versus a novel combined suture to control bleeding from the placental bed in complete placenta previa at caesarean section.

Methods: One hundred and six women with postpartum hemorrhage during cesarean section for placenta previa centralis, were included and randomly assigned into two groups, the first $(n=54)$ underwent bilateral uterine artery ligation and square sutures in each uterine wall without opposition, and the second $(n=52)$ underwent a novel combined suture that traverses the right lateral wall making a square taking the uterine artery on the right side. Arrest of bleeding from the placental bed with no need for further surgical interventions, the rate of subsequent intrauterine synechiae and menstrual irregularity after three months was the main outcome measures. Data was collected and tabulated.
\end{abstract}

Results: The novel procedure was successful in 48 patients (92.3\%) compared to $81.5 \%$ in the first group

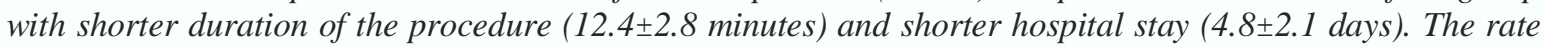
of subsequent intrauterine synechiae was $9.6 \%$ and of menstrual irregularity was $7.8 \%$ after the novel procedure.

Conclusion: The novel combined suture is easily applicable and effectively controls bleeding from the placental bed after failure of conservative measures, with no appreciable increase in short term maternal morbidity. Larger multicenter trials are warranted to enforce or refute these findings.

Keywords: postpartum hemorrhage, placenta previa, novel procedure, uterine artery ligation, square suture

\section{INTRODUCTION}

Placenta previa becomes a major health problem secondary to significant increases in maternal and fetal morbidity and mortality with estimated prevalence between $0.2-0.3 \%$ of all pregnancies at the third trimester $(1,2)$.

Placenta previa and accreta may cause massive life-threatening intrapartum and postpartum hemorrhage which necessitates multidisciplinary management plans to achieve better obstetric outcome $(3,4)$.

The traditional surgical techniques to achieve hemostasis if severe bleeding ensues, is rapid resort to artery ligation or cesarean hysterectomy $(1,4)$.Several uterine compression techniques were introduced to conserve the uterus including B-Lynch suture (5), Cho multiple square sutures (6) and Hayman compression sutures (7) with variable success rates. Fewer studies in the literature address the use of uterine compression sutures to stop bleeding from the placental bed in placenta previa $(8,9)$.

The aim of this study was to assess the efficacy and safety of bilateral uterine artery ligation and square sutures versus a novel combined suture to control bleeding from the placental bed in complete placenta previa at cesarean section.

\section{MATERIALS AND METHODS}

This randomized parallel group study was conducted at the Operating room at the 
Bilateral Uterine Artery Ligation and Square Sutures versus a Novel Combined Suture for Controlling Bleeding from the Placental Bed in Placenta Previa Centralis at Cesarean Section: A Randomized Clinical Trial

Department of Obstetrics and Gynecology, Faculty of Medicine, Menoufia University, Shibin El-kom city, Menoufia governorate, Egypt in the period between the middle of October 2016 and the end of May 2017.

The Ethical committee for medical research at Menoufia Faculty of Medicine reviewed and formally approved the study protocol with all participants signed an informed consent form prior to commencement of the study.

The sample size was actually calculated based on assumption of expected difference between

both groups of $10 \%$ regarding the success rate in arresting uterine hemorrhage. This would be detectable using a sample size of 50 patients per group with $80 \%$ power and $\alpha$ level of 0.05 .

The study was conducted on 113 healthy women who presented with the diagnosis of placenta previa centralis before delivery. (Figure 1: CONSORT flow diagram)

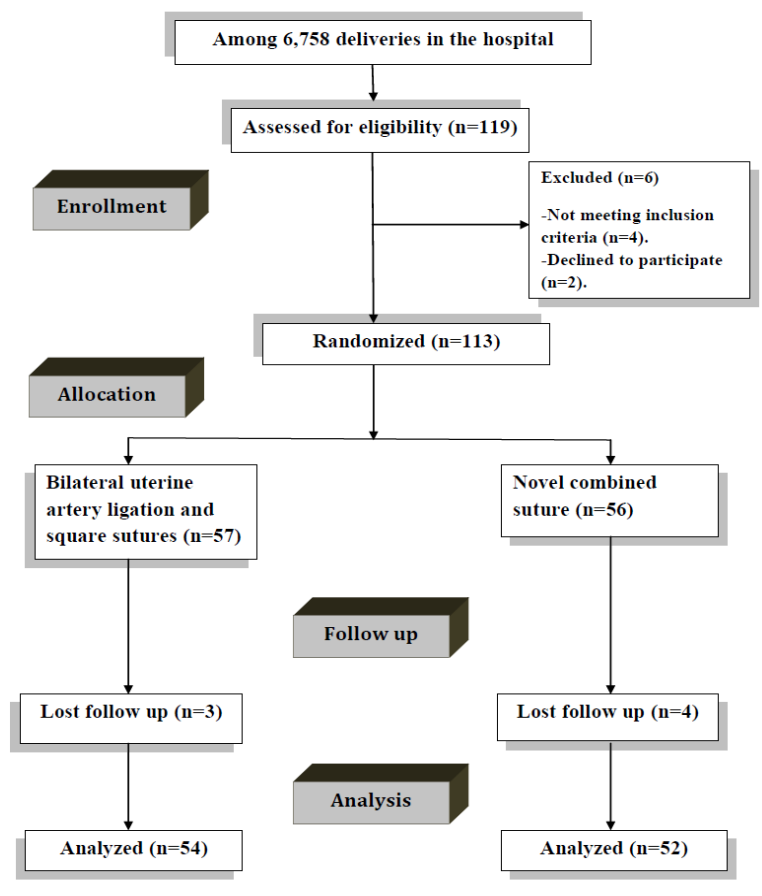

Figure1. CONSORT Flow Diagram

Patients with known bleeding tendency, morbid obesity, heart disease, renal or hepatic diseases, any severe chronic disease, multiple pregnancy as well as patients with placenta accreta at cesarean section diagnosed on clinical basis (difficult removal of the placenta) were excluded from the study. Randomization in 1:1 ratio was carried out using computer-generated simple random tables with patients allocated into two groups:

Group 1 (n=54): underwent bilateral uterine artery ligation and square sutures. A bilateral uterine artery ligation followed by square sutures were taken in each uterine wall without opposition of the anterior and posterior walls to avoid closure of the cervical canal which is different from those previously described by Cho (6). (As illustrated in figure 2).

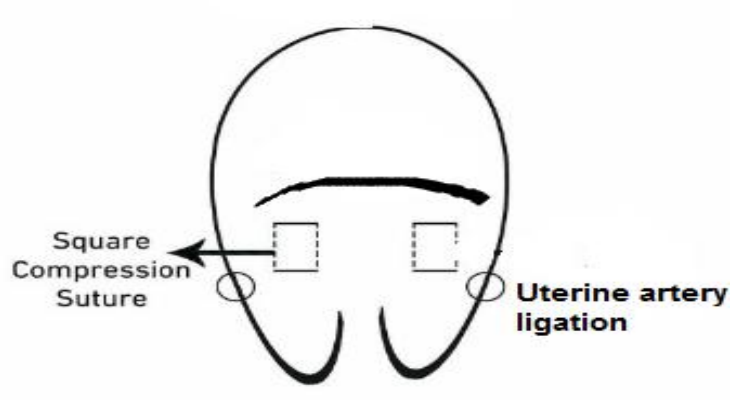

Figure2. Bilateral uterine artery ligation and square sutures

Group 2 ( $\mathbf{n = 5 2})$ : combined suture placed in the lower uterine segment (LUS) to include the right uterine artery and part of the LUS.

After transverse incision, delivery of the fetus and complete removal of the placenta, the incised edge of the anterior wall of the LUS was grasped with an Allis clamp and pulled forward and upward. The combined suture was applied using no.1, vicryl 50-mm curved, round needle to place the first stitch entry through the anterior wall of the LUS one $\mathrm{cm}$ medial to its margin and about $6 \mathrm{~cm}$ below the edge of uterine incision and just above the opening of the cervix. The needle penetrates the whole thickness of both anterior and posterior uterine walls (point A). Then from the insertion point of point $A$, the needle passes from posterior to anterior through a vascular window in the broad ligament lateral to uterine artery and the knot tied an teriorly at point $A$ and not cut leaving long part of thread material for final knot.

The needle passes upward above point $\mathrm{A}$ to reach (point $\mathrm{B}$ ) one $\mathrm{cm}$ medial to the margin of the lower segment and about two $\mathrm{cm}$ below the edge of uterine incision then penetrates the whole thickness of both anterior and posterior uterine wall from anterior to posterior. Then from insertion point of point $B$ the needle pass from posterior to anterior through a vascular window in the broad ligament lateral to uterine artery which not tied.

From the insertion point of point $\mathrm{C}$ the needle passes downward to reach ( point D) which lies one $\mathrm{cm}$ medial and at the same level of point $\mathrm{A}$ 
Bilateral Uterine Artery Ligation and Square Sutures versus a Novel Combined Suture for Controlling Bleeding from the Placental Bed in Placenta Previa Centralis at Cesarean Section: A Randomized Clinical Trial

to penetrate the whole thickness of the uterus from posterior to anterior ( point D) to emerge
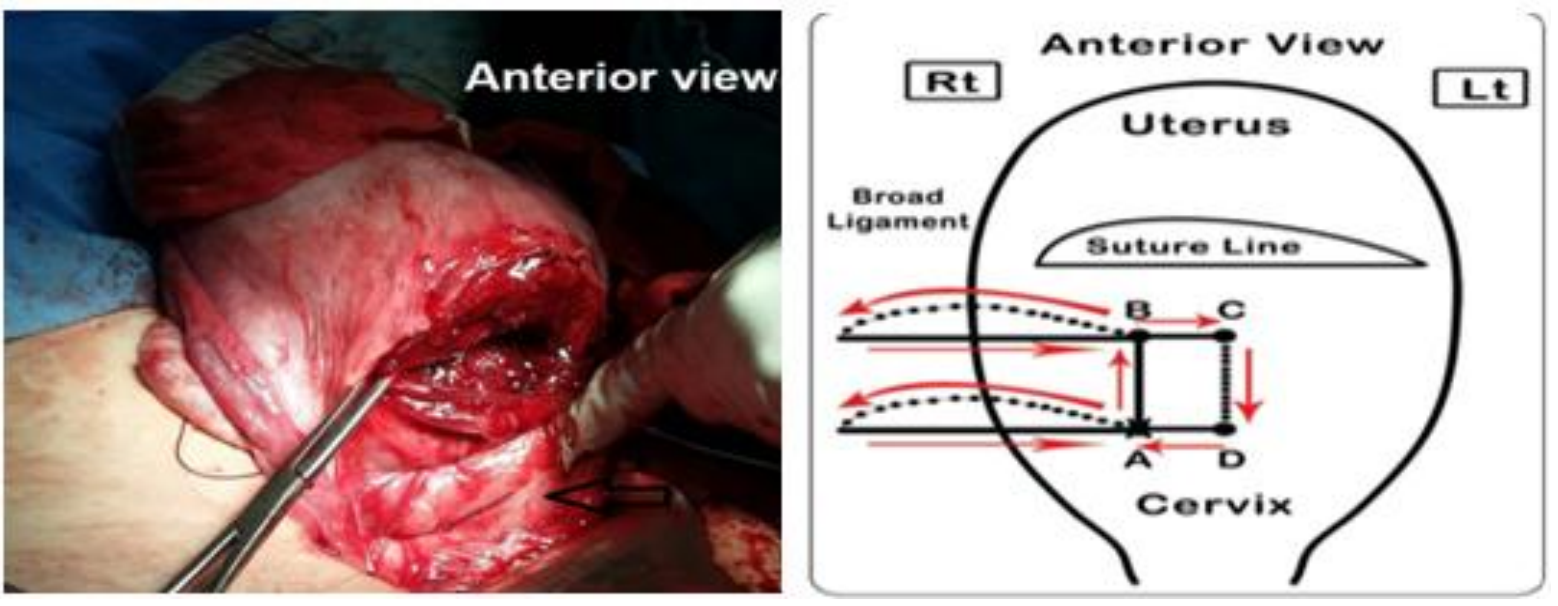

Figure3A. Anterior view of the novel combined technique
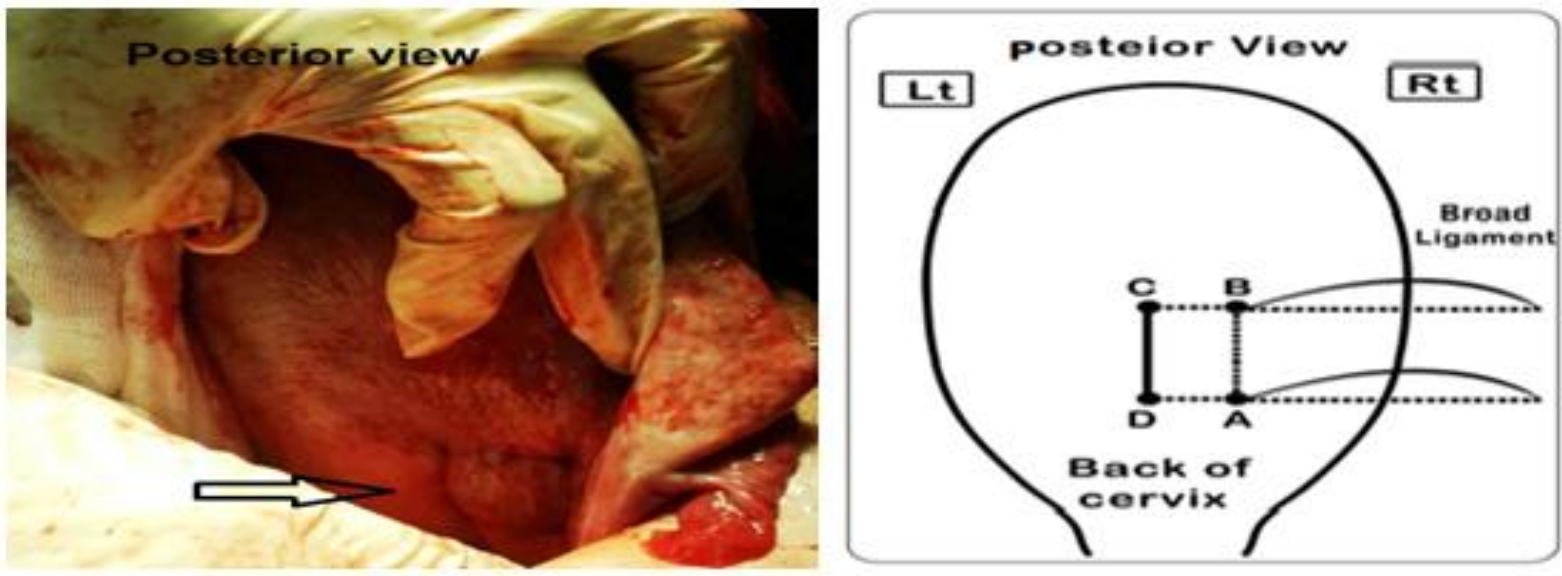

Figure3B. Posterior view of the novel combined technique

Finally the knots were tied anteriorly at level of point A to oppose the anterior and posterior walls in the lower segment of the uterine cavity (As illustrated in figure 3 )

Both surgical procedures were started after initial conservative measures and administration of uterotonics have been failed.

\section{In Either Technique}

The patency of cervical canal was confirmed by Hegar dilator, artery clamp or Nilaton catheter before closure of the caesarean section incision. The uterine incision and abdominal wall layers were closed as usual.

Intravenous triple antibiotic therapy was administered for 72 hours in the form of Ampcillin 1 gm every 6 hours, Garamycin 80 mg every 8 hours and Metronidazole infusion bottle $500 \mathrm{mg}$ every 12 hours.

On the third postoperative day and before discharge from hospital, trans-abdominal ultrasound was performed using Mindray DP-30 portable ultrasound machine (Mindray, China), to ensure absence of fluid or blood accumulating in the uterine cavity.

Follow up visits every 2-3 weeks was attained until 12 weeks postpartum to assess any adverse effects of the procedure. Office hysteroscopy and Saline infusion sonohystrography (SIS) using Mindray DP-30 portable ultrasound machine (Mindray, China), were done to all cases to exclude intra uterine synechia by different observers who were blinded to the surgical procedure performed at the time of delivery.

\section{OUTCOME MEASURES}

\subsection{Primary Outcome}

Efficacy of the procedure (defined as arrest of bleeding with no need for further interventions). 
Bilateral Uterine Artery Ligation and Square Sutures versus a Novel Combined Suture for Controlling Bleeding from the Placental Bed in Placenta Previa Centralis at Cesarean Section: A Randomized Clinical Trial

\subsection{Secondary Outcome}

Included duration of the procedure and short term adverse effects. Menstrual irregularity was defined as frequency of menstruation less than 21 days or more than 35 days in the preceding months.

\section{Statistical Analysis}

Data was analyzed with an IBM computer using the SPSS 22 statistical software package (SPSS Inc., Chicago, IL). Student's t test was used for comparing means of two normally distributed continuous variables while Mann-Whitney test was used for non-parametric variables. Chi square and Fischer's exact tests were used for comparison of categorical variables. $\mathrm{P}$-value $\leq$ 0.05 was statistically significant and $<0.001$ was highly significant.

\section{Results}

Table (1) depicts patients' characteristics. There was no significant difference between both groups regarding age, parity, body mass index and past obstetric history ( $\mathrm{p}>0.05)$.
Table1. Patient characteristics

\begin{tabular}{|l|l|l|l|l|}
\hline & $\begin{array}{c}\text { Group 1 } \\
(\mathbf{n = 5 4})\end{array}$ & $\begin{array}{c}\text { Group 2 } \\
\text { (n=52) }\end{array}$ & $\begin{array}{c}\text { Student } \\
\text { t-test }\end{array}$ & $\begin{array}{l}\text { P- } \\
\text { value }\end{array}$ \\
\hline $\begin{array}{l}\text { Age } \\
\text { (years) }\end{array}$ & $25.6 \pm 5.1$ & $26.2 \pm 5.8$ & 0.57 & $>0.05$ \\
\hline Parity & $2.2 \pm 1.6$ & $2.3 \pm 1.4$ & $0.37^{*}$ & $>0.05$ \\
\hline $\begin{array}{l}\text { Body } \\
\text { mass } \\
\text { index } \\
\text { (Kg/m })\end{array}$ & $24.4 \pm 4.1$ & $24.7 \pm 3.9$ & 0.39 & $>0.05$ \\
\hline $\begin{array}{l}\text { Past } \\
\text { obstetric }\end{array}$ & & & & \\
history: & & & & \\
-Previous & & & & \\
sharp & & & & \\
curettage & 15 & 17 & 0.12 & $>0.05$ \\
-One CS & 30 & 25 & 0.33 & $>0.05$ \\
-Two CS & 9 & 10 & 0.01 & $>0.05$ \\
\hline
\end{tabular}

*Mann Whitney test, CS=Caesarean section.

Table (2) reveals the operative data. There was no significant difference between both groups regarding success rate, type of anesthesia, type of skin incision, estimated blood loss and organ injury ( $p>0.05)$. The duration of the procedure was shorter in group $2 \quad(p<0.001)$

Table2. Operative data

\begin{tabular}{|c|c|c|c|c|c|}
\hline & $\begin{array}{l}\text { Group } \\
(\mathbf{n}=54)\end{array}$ & $\begin{array}{l}\text { Group } \\
(\mathbf{n}=52)\end{array}$ & $\begin{array}{ll}\text { Chi } & \text { square } \\
\text { test } & \end{array}$ & P-value & $\begin{array}{l}\text { Odds ratio at } 95 \% \\
\text { CI }\end{array}$ \\
\hline $\begin{array}{l}\text { Success } \\
\text { Failure: } \\
\text {-Internal iliac } \\
\text { artery ligation } \\
\text {-Supravaginal } \\
\text { hysterectomy } \\
\end{array}$ & $\begin{array}{l}44(81.5 \%) \\
10(18.5 \%) \\
4 \\
6\end{array}$ & $\begin{array}{l}48(92.3 \%) \\
4(6.7 \%) \\
2 \\
2 \\
\end{array}$ & 1.85 & $>0.05$ & $0.37(0.11-1.25)$ \\
\hline $\begin{array}{l}\text { Type } \\
\text { anesthesia: } \\
\text {-General } \\
\text {-Regional }\end{array}$ & $\begin{array}{l}25 \\
29\end{array}$ & $\begin{array}{l}20 \\
32\end{array}$ & 0.38 & $>0.05$ & $1.38(0.64-2.9)$ \\
\hline $\begin{array}{l}\text { Type of skin } \\
\text { incision: } \\
\text {-Pfannenstiel } \\
\text {-Midline }\end{array}$ & $\begin{array}{l}28 \\
26\end{array}$ & $\begin{array}{l}28 \\
24\end{array}$ & 0.001 & $>0.05$ & $0.92(0.43-1.98)$ \\
\hline $\begin{array}{l}\text { Duration of the } \\
\text { procedure } \\
\text { (minutes) }\end{array}$ & $18.6 \pm 4.8$ & $12.4 \pm 2.8$ & $8.08^{*}$ & $<0.001$ & - \\
\hline $\begin{array}{l}\text { Estimated blood } \\
\text { loss }(\mathrm{mL})\end{array}$ & $880.8 \pm 480.6$ & $870.2 \pm 490.4$ & $0.11^{*}$ & $>0.05$ & - \\
\hline $\begin{array}{l}\text { Organ injury: } \\
\text {-Bladder } \\
\text {-Ureter }\end{array}$ & $\begin{array}{l}6 \\
2\end{array}$ & $\begin{array}{l}1 \\
1\end{array}$ & $\begin{array}{l}2.29 \dagger \\
0.001 \dagger\end{array}$ & $\begin{array}{l}>0.05 \\
>0.05\end{array}$ & $\begin{array}{l}6.38(0.74-54.9) \\
1.96(0.17-22.3)\end{array}$ \\
\hline
\end{tabular}

*Student $t$-test, $\uparrow$ Fischer's exact test.

Table (3) shows postoperative data. There was no significant difference between both groups regarding blood transfusion, re-operation,
Admission to ICU, early and late postoperative complications $(p>0.05)$. The duration of the hospital stay was shorter in group $2(\mathrm{p}<0.001)$. 
Bilateral Uterine Artery Ligation and Square Sutures versus a Novel Combined Suture for Controlling Bleeding from the Placental Bed in Placenta Previa Centralis at Cesarean Section: A Randomized Clinical Trial

Table3. Post-operative data

\begin{tabular}{|c|c|c|c|c|c|}
\hline & $\begin{array}{l}\text { Group } \\
(n=54)\end{array}$ & $\begin{array}{l}\text { Group } \\
(\mathbf{n}=52)\end{array}$ & $\begin{array}{l}\text { Fischer's exact } \\
\text { test }\end{array}$ & P-value & $\begin{array}{l}\text { Odd's ratio at } 95 \% \\
\text { CI }\end{array}$ \\
\hline $\begin{array}{l}\text { Blood transfusion: } \\
\text {-Packed RBCs } \\
\text {-Fresh frozen plasma } \\
\text {-Both }\end{array}$ & $\begin{array}{l}9 \\
4 \\
2 \\
3 \\
\end{array}$ & $\begin{array}{l}4 \\
1 \\
2 \\
1 \\
\end{array}$ & 1.16 & $>0.05$ & $2.35(0.68-8.16)$ \\
\hline $\begin{array}{l}\text { Re-operation for } \\
\text { organ injury }\end{array}$ & 4 & 2 & 0.14 & $>0.05$ & $2(0.35-11.4)$ \\
\hline Admission to ICU & 4 & 1 & 0.76 & $>0.05$ & $4.08(0.44-37.7)$ \\
\hline Hospital stay (days) & $8.6 \pm 5.1$ & $4.8 \pm 2.1$ & 4.98 & $<0.001$ & - \\
\hline $\begin{array}{l}\text { Early postoperative } \\
\text { complications: } \\
\text {-Fever } \\
\text {-VTE } \\
\text {-SSI } \\
\end{array}$ & $\begin{array}{l}6 \\
4 \\
3 \\
\end{array}$ & $\begin{array}{l}2 \\
2 \\
1 \\
\end{array}$ & $\begin{array}{l}1.1 \\
0.14 \\
0.22 \\
\end{array}$ & $\begin{array}{l}>0.05 \\
>0.05 \\
>0.05\end{array}$ & $\begin{array}{l}3.13(0.6-16.25) \\
2(0.35-11.4) \\
3(0.3-29.8) \\
\end{array}$ \\
\hline $\begin{array}{l}\text { Late postoperative } \\
\text { complications: } \\
\text {-Menstrual } \\
\text { irregularity } \\
\text {-Intrauterine } \\
\text { synechiae }\end{array}$ & $\begin{array}{l}7 \\
8\end{array}$ & $\begin{array}{l}4 \\
5\end{array}$ & $\begin{array}{l}0.33 \\
0.27 \dagger\end{array}$ & $\begin{array}{l}>0.05 \\
>0.05\end{array}$ & $\begin{array}{l}1.79(0.49-6.5) \\
1.63(0.5-5.37)\end{array}$ \\
\hline Maternal mortality & 0 & 0 & - & - & - \\
\hline
\end{tabular}

*Student $t$-test, + Chi square test, VTE=Venous thromboembolism, SSI=Surgical site infection

\section{DISCUSSION}

The novel technique has the advantages of approximating both anterior and posterior parts of lower uterine segment creating a closed square which helps in closing bleeding sinuses and superficial tears in the lower uterine segment. This is in addition to occluding the uterine artery at two different levels making the uterine devascularization more effective. It takes few minutes to achieve hemostasis (12.4 \pm 2.8 minutes) with high success rate $(92.3 \%)$ in avoiding hysterectomy with lower rate of developing subsequent intrauterine synechiae $(9.6 \%)$.

Hwu's et al (10) previously described a suture that it might avoid injuring the adjacent organs because the stitch does not penetrate through the whole posterior wall. However, this suture increases suturing difficulty because Hwu's suture requires sewing inside the lower uterine cavity and inserting a needle directed vertically upward 3-4 $\mathrm{cm}$ within the posterior uterine wall, which may injure the thin friable lower uterine segment, especially when the entire cavity is filled with blood. Hence, full-thickness sutures may work better as it is simpler to do.

More recently in the study conducted by Guang et al (11) fifteen women received a longitudinal parallel compression suture to stop bleeding due to placenta previa with or without accreta during caesarean section after closure of suture line, The success rate of the procedure was $86.7 \%$ $(13 / 15)$. The novel combined suture used in this study is more advantageous in terms of higher success rate $(92.3 \%)$, more hypoperfusion achieved with uterine artery occlusion which is demonstrable before closure of the cesarean section incision.

Several adverse effects of uterine compression sutures have been reported as infections in the form of endometritis or pyometra $(12,13)$, intrauterine synechiae and Asherman syndrome (14-16) leading some authors to recommend routine postoperative evaluation of the uterine cavity by imaging modality or hysteroscopy $(17,18)$. Also, many case reports of uterine wall necrosis following combined B-Lynch and/or Cho square sutures (19-21), uterine rupture (22) 
Bilateral Uterine Artery Ligation and Square Sutures versus a Novel Combined Suture for Controlling Bleeding from the Placental Bed in Placenta Previa Centralis at Cesarean Section: A Randomized Clinical Trial

and uteroumbilical fistula with myometrial necrosis (23) have been published.

There were no cases with endometritis reported in this trial which may be linked to confirmation of cervical patency before closing the uterine incision, the use of triple antibiotic therapy for three days and the assurance of absence of any fluid or blood collected inside the uterine cavity before discharge from the hospital. Also, the rate of intrauterine synechiae with the use of the novel combined suture was $9.6 \%$ which is far away less than the rates previously described in earlier studies with compression sutures, which lies between 16-23\% (14-16).

Secondary to complications of uterine compression sutures, some investigators addressed the use of removable uterine compression suture $(24,25)$, which is tried in small number of patients with no long-term follow up data available.

The use of two different types of anesthesia and skin incisions during cesarean sections may constitute unintended limitations of this study.

Future research should compare between the standard compression sutures and the novel procedure described in this study in a larger multicenter study.

\section{CONCLUSION}

The novel combined suture is easily applicable and effectively controls bleeding from the placental bed after failure of conservative measures, with no appreciable increase in short term maternal morbidity. Larger multicenter trials are warranted to enforce or refute these findings.

\section{ACKNOWLEDGEMENTS}

The authors would like to acknowledge the contribution of residents and nursing staff at the delivery room and Blood Bank of Menoufia University hospital.

Ethical approval: All procedures performed in the current study involving human participants were in accordance with the ethical standards of the Menoufia Fcaulty of Medicine research committee and with the 1964 Helsinki declaration and its later amendments. The study was approved by Institutional review board of Obstetrics and Gynaecology department, Letter Number (326H/2016). Registered in accordance with WHO and ICMJE standards at Pan African Clinical Trials Registry at www.pactr.org with trial registration number PACTR201610001803 327 Date registered: 2016/10/03.

Informed consent: Informed consent was obtained from all individual participants included in the study.

\section{REFERENCES}

[1] American College of Obstetricians and Gynecologists. ACOG Practice Bulletin. Clinical Management Guidelines for ObstetriciansGynecologists. Number 76, October 2006: postpartum hemorrhage. Obstet Gynecol 2006; 108:1039-47.

[2] Faranesh R, Shabtai R, Eliezer S. and Raed S. Suggested approach for management of placenta percreta invading the urinary bladder. Obstet Gynecol 2007; 11): 512-15.

[3] Rosenberg T, Pariente G, Sergienko R, Wiznitzer A, Sheiner E Critical analysis of risk factors and outcome of placenta previa. Arch Gynecol Obstet 2010; 284:47-51.

[4] Rao KP, Belogolovkin V, Yankowitz J, Spinnato JA. Abnormal Placentation: EvidenceBased Diagnosis and Management of Placenta Previa, Placenta Accreta, and Vasa Previa. Obstet Gynecol survey 2012; 67: 503-519.

[5] 5-B-Lynch C, Coker A, Lawal AH, Abu J, Cowen MJ. The B-Lynch surgical technique for the control of massive postpartum haemorrhage: an alternative to hysterectomy? Five cases reported. BJOG 1997; 104:372-5.

[6] Cho JH, Jun HS, Lee CN. Hemostatic suturing technique for uterine bleeding during cesarean delivery. Obstet Gynecol 2000; 96:129-131.

[7] Hayman RG, Arulkumaran S, Steer PJ. Uterine compression sutures: surgical management of 
Bilateral Uterine Artery Ligation and Square Sutures versus a Novel Combined Suture for Controlling Bleeding from the Placental Bed in Placenta Previa Centralis at Cesarean Section: A Randomized Clinical Trial

postpartum hemorrhage. Obstet Gynecol 2002; 99:502-7.

[8] Zhu L, Zhang Z, Wang H, Zhao J, He X, Lu J. A modified suture technique for hemorrhage during cesarean delivery complicated by complete placenta previa. Int J Gynaecol Obstet. 2015; 129(1):26-9.

[9] Li GT, Li XF, Wu B, Li G. Longitudinal parallel compression suture to control postopartum hemorrhage due to placenta previa and accrete. Taiwan J Obstet Gynecol. 2016; 55(2):193-7.

[10] Hwu YM, Chen CP, Chen HS, Su TH. Parallel vertical compression sutures: a technique to control bleeding from placenta praevia or accreta during caesarean section. BJOG 2005; 112:1420-3

[11] Guangrui A, Baoping W, Xiao-Fan Li , Guang -Tai Li. Longitudinal parallel compression suture to control postopartum hemorrhage due to placenta previa and accrete. Taiwan J Obstet Gynecol. 2016; 55:193-97.

[12] Liu S, Mathur M, Tagore S. Complications and pregnancy outcome following uterine compression suture for postpartum haemorrhage: a single centre experience. J Obstet Gynaecol. 2014; 34(5):383-6.

[13] Loaec C, Nowak C, Lopes P, Winer N. Obstetric outcomes after uterine compression suture for treatment of postpartum hemorrhage: Long-term monitoring of 40 cases. Gynecol Obstet Fertil. 2015; 43(7-8):509-14.

[14] Rathat G, Do Trinh P, Mercier G, Reyftmann L, Dechanet C, Boulot P, Giacalone PL. Synechia after uterine compression sutures. Fertil Steril. 2011; 95(1):405-9.

[15] Ibrahim MI, Raafat TA, Ellaithy MI, Aly RT. Risk of postpartum uterine synechiae following uterine compression suturing during postpartum haemorrhage. Aust N Z J Obstet Gynaecol. 2013; 53(1):37-45.
[16] Jamard A, Turck M, Chéret-Benoist A, Dreyfus M, Benoist G. Risk of uterine synechiae following uterine compression sutures during postpartum haemorrhage. Gynecol Obstet Fertil. 2014; 42(10):681-5.

[17] Poujade O, Grossetti A, Mougel L, Ceccaldi PF, Ducarme G, Luton D. Risk of synechiae following uterine compression sutures in the management of major postpartum haemorrhage. BJOG. 2011; 118(4):433-9.

[18] Amorim-Costa C, Mota R, Rebelo C, Silva PT. Uterine compression sutures for postpartum hemorrhage: is routine postoperative cavity evaluation needed? Acta Obstet Gynecol Scand. 2011; 90(7):701-6.

[19] Akoury H, Sherman C. Uterine wall partial thickness necrosis following combined BLynch and Cho square sutures for the treatment of primary postpartum hemorrhage. J Obstet Gynaecol Can. 2008; 30(5):421-4.

[20] Reyftmann L, Nguyen A, Ristic V, Rouleau C, Mazet N, Dechaud H. Partial uterine wall necrosis following Cho hemostatic sutures for the treatment of postpartum hemorrhage. Gynecol Obstet Fertil. 2009; 37(6):579-82.

[21] Lodhi W, Golara M, Karangaokar V, Yoong W. Uterine necrosis following application of combined uterine compression suture with intrauterine balloon tamponade. $\mathrm{J}$ Obstet Gynaecol. 2012; 32(1):30-1.

[22] Higgins L, Chan KL, Tower C. Uterine rupture following previous uterine compression suture. J Obstet Gynaecol. 2011; 31(6):544.

[23] Rashmi MD, Lokeshchandra HC, Chaitra TM. Uteroumbilical fistula with myometrial necrosis following compression suture for atonic PPH: a rare case. Arch Gynecol Obstet. 2013; 287(5):1045-6.

[24] Aboulfalah A, Fakhir B, Ait Ben Kaddour Y, Asmouki H, Soummani A. A new removable 
Bilateral Uterine Artery Ligation and Square Sutures versus a Novel Combined Suture for Controlling Bleeding from the Placental Bed in Placenta Previa Centralis at Cesarean Section: A Randomized Clinical Trial

uterine compression by a brace suture in the management of severe postpartum hemorrhage. Front Surg. 2014; 1:43.
[25] Zhang ZW, Liu CY, Yu N, Guo W. Removable uterine compression sutures for postpartum haemorrhage. BJOG. 2015; 122(3):42

Citation: Mohamed Rezk, Ibrahim Saif El-Nasr. Bilateral Uterine Artery Ligation and Square Sutures versus a Novel Combined Suture for Controlling Bleeding from the Placental Bed in Placenta Previa Centralis at Cesarean Section: A Randomized Clinical Trial. ARC Journal of Gynecology and Obstetrics 2017; 2(3): 13-20. DOI: dx.doi.org/10.20431/2456-0561.0203004

Copyright: (C) 2017 Authors. This is an open-access article distributed under the terms of the Creative Commons Attribution License, which permits unrestricted use, distribution, and reproduction in any medium, provided the original author and source are credited. 